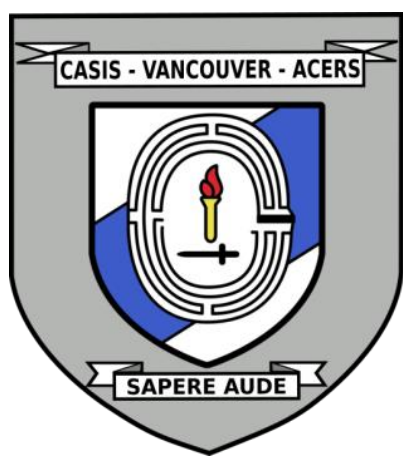

\title{
A SOLUTION-BASED APPROACH TO CIVIL DISCOURSE
}

Date: November 24, 2021

Disclaimer: This briefing note contains the encapsulation of views presented by the speaker and does not exclusively represent the views of the Canadian Association for Security and Intelligence Studies.

\section{KEY EVENTS}

On November 24, 2021, Ms. Elise Labott, leading foreign policy journalist, presented A Solution-Based Approach to Civil Discourse at the 2021 CASIS West Coast Security Conference. Primary discussion topics included the definition of 'broken' media, a brief overview of racism throughout history, the consequences of echo chambers and online trolling, and a potential solution to improve and encourage civil discourse online. The presentation was followed by a question and answer period with questions from the audience and CASIS Vancouver executives.

\section{NATURE OF DISCUSSION}

\section{Presentation}

Ms. Labott's presentation highlighted the reasons why she believes the media is broken, the importance of civil discourse online, and potential solutions that Zivvy Media can provide. Ms. Labott's presentation also touched on how eco chambers are perpetuating polarization and misinformation.

\section{Question Period}

During the question and answer period, Ms. Labott discussed the ways in which a broken media system may be more prevalent in the United State than elsewhere. In addition, she engaged in a dialogue about the importance of media literacy and critical thinking when engaging with the media. 


\section{BACKGROUND}

\section{Presentation}

Ms. Labott began her presentation by examining the reasons why she considers the media to be broken today. One could argue that nowadays the media is biased, elitist, and exclusive. Ms. Labott noted that bias is shown through the failure to present all sides, leading to a lack of consensus and fueling polarization. Furthermore, she argued that the media serves the elite as there is often a lack of diversity. In Washington, she noted, discussion about foreign policy is said to be "pale, male, and Yale" because often it is only a certain type of people explaining what security means to the outside world, leaving out the developing world. Ms. Labott also pointed out that young people tend to be excluded from conversations about issues that shape their future.

Ms. Labott noted that when people do not hear about issues that are important to them in the media, they turn to the online environment. Online echo chambers have limited sources and perspectives and confirm biases. The online environment is not controlled/patrolled, which decreases accountability and increases disinformation, and as the threshold to present those views lowers, the likelihood of violence increases.

Ms. Labott explained that the sense of 'the other' has been present throughout history. Before the Internet, institutionalized racism and anti-Black sentiment was already present, and the post-9/11 War on Terror fueled Islamophobia and anti-Muslim sentiment. Now, COVID-19 has spiked hate crimes against AsianAmericans and Pacific Islanders as they blame them for the origins of COVID19. According to Ms. Labott, what we are experiencing now is different because it comes from a different context, and it seems to be morphing with other 'anti' common causes and white nationalism. Furthermore, hatred, bullying, and misinformation has become more pervasive online.

Ms. Labott then explained how online trolling can have serious, long-term mental health implications even for children. As we move into the next generation, online trolling will result in fear of engagement, fracture the ability to communicate, and discourage civil discourse. Ms. Labott explained that polarization will continue unless we teach young people to communicate with one another and not to be afraid. Ms. Labott believes that creating solutions-based conversations are necessary to find some common ground and move us from a 'me vs. you' to an 'us vs. the problem' approach, which will allow us to counter polarization. Through intergenerational and intersectional conversations, we can 
create a safe ecosystem where people can provide different opinions and share their concerns to find solutions to the problem.

Ms. Labott highlighted that it is crucial to include Gen Zs in these conversations that will shape their future. Seeing the need for inclusivity and common ground among younger generations, Ms. Labott decided to start Zivvy Media-which comes from the German term 'zivilcourage,' meaning moral courage - a digital platform designed for Gen Zs and Millennials. This platform is at the intersection of media and civic engagement for future leaders and next generation changemakers. Ms. Labott noted that engaging in intergenerational and intersectional conversations takes courage, and this platform allows people to learn from, and speak to, others who have different perspectives than them. These conversations will not only create a more pluralistic society but also improve security.

Zivvy's objective is to build a community that allows a two-way dialogue across the platform's channels, develop discerning media consumers that will help break through echo chambers, and empower future changemakers by inviting them to search for answers and become more informed. Zivvy provides jargon-free, factbased balanced content; community engagement through different town halls and live events; and partnership with academics, who encourage civic engagement and civil discourse.

Ms. Labott concluded her presentation by providing an overview of the Zivvy model, which she noted is a unique journey that goes from informing to making change, while removing polarization and building a big tent community. The model is built to inform, engage, inspire, and empower its audience. If everyone collaborates and provides different perspectives, polarization can be reduced.

\section{Question Period}

During the question and answer period, Ms. Labott was asked whether her criticism of American media and online spaces as being biased, polarizing, exclusive, and elitist was a uniquely American problem. She countered that while it is visible in other countries as well, it is perhaps a more pervasive problem in the United States because of the freedom that the press is given and the difficulty in deciphering where the line should be drawn. There are similar questions about how social media is regulated because social media sites are becoming more like news organizations as they become aggregators of news and contribute to the fueling of polarization. 
In a discussion with the panel about disinformation in online echo chambers, Ms. Labott expressed her views about the importance of media literacy. While one can work to dismantle the algorithms and trolls that contribute to the spread of information, we need to also look at the audience receiving this information and ask why they are not more discerning. This initiated a conversation about critical thinking and the importance of questioning information and where it comes from.

\section{KEY POINTS OF DISCUSSION}

\section{Presentation}

- One could argue that bias, elitism, and exclusivity are the reasons the media is now 'broken.'

- Online echo chambers are uncontrolled environments that provide limited sources and perspectives, which then confirm biases, decrease accountability, and increase disinformation.

- Online trolling can have serious mental health implications as it discourages engagement, fractures communication, and discourages civil discourse.

- Through intergenerational and intersectional conversations, we can create an ecosystem where people can bring different opinions and concerns to the table and find solutions to the 'me vs. you' problem.

- Zivvy Media is a digital platform for the next generation of changemakers. It provides fact-based balanced content and a safe space to connect, discuss issues, and brainstorm solutions.

\section{Question Period}

- Although the issues of the media being 'broken' is not solely an American problem, it may be greater in the United States than elsewhere because of the freedoms given to the press.

- There needs to be more emphasis on media literacy and critical thinking to equip audiences with the ability to question the validity of information and its origin. 


\section{(ब) $\odot$} Commercial-NoDerivatives 4.0 International License.

(C) (ELISE LABOTT, 2022)

Published by the Journal of Intelligence, Conflict, and Warfare and Simon Fraser University

Available from: https://jicw.org/ 